\title{
Intermathematic Possibilities: IOC, Plane Of Immanence And The Architecture Of The Concepts
}

\author{
Juliano Bona ${ }^{*}$ \\ Camila Thaisa Alves Bona ${ }^{* *}$ \\ José Marcelo Freitas de Luna ${ }^{* * *}$
}

\begin{abstract}
When we think of mathematics we feel we are facing a kind of universal knowledge that brings us closer to the truth. Transcendence is the space where we place this kind of objectification of mathematics. However, criticism of this type of hegemonic mathematics has been growing in recent years. In the face of hegemony and criticism, the objective of this article is to analyze internationalization of the curriculum (IoC) as the plane of immanence, and the process of conceptual construction in the field of philosophy. On these bases which in some ways represent the background that supports the critique of hegemonic mathematics, we can think of other possibilities that we call intermathematics. As an essay text, it follows theoretical contribution: BACHELARD (2008), BICUDO (1993), CANDAU (2002), DELEUZE (2000), DELEUZE (1996), FOUCAULT (2013), LEASK (20015), LUNA (2016), SANTOS (2002), SILVA (2010). To achieve the general objective, we divide the analysis into three parts. First, we approach the relationship between IoC and the immanence plan in the field of mathematics education. In a second moment, we discuss the idea of the plane of immanence and the IoC. Finally, we articulate methodological aspects, the plane of immanence and the conceptual construction process in an attempt to construct intermathematic possibilities. In this movement, we emphasize not only criticism of hegemonic mathematics, but also we indicate the ways of thinking mathematics in immanence through geo-mathematics, ethnomathematics and intermathematics.

Keywords: Plane of immnence, Internationalization of Curriculum, Education Matemathics Education, Intermathematics.

\footnotetext{
* Universidade do Vale do Itajaí. Itajaí, Santa Catarina, Brasil. E-mail: bonajuliano@gmail.com. Orcid: https://orcid.org/0000-0001-7180-2041

** Universidade do Vale do Itajaí. Itajaí, Santa Catarina, Brasil. E-mail: camilatalves@gmail.com. Orcid: https://orcid.org/0000-0003-1167-3924

*** Universidade do Vale do Itajaí. Itajaí, Santa Catarina, Brasil. E-mail: mluna@univali.br. Orcid: https://orcid.org/0000-0002-1212-7899
} 


\section{Possibilidades Intermatemáticas: A IOC, O Plano de Imanência e a Arquitetura dos Conceitos}

\section{Resumo:}

Quando pensamos na matemática, temos a sensação de estarmos diante de um tipo de conhecimento universal, que nos aproxima da verdade. A transcendência é o espaço onde situamos este tipo de objetivação da matemática. Porém, a crítica a este tipo de matemática hegemônica vem crescendo nos últimos anos. Diante da hegemonia e da crítica, o objetivo desse artigo é analisar, a IoC, o plano de imanência, e o processo de construção conceitual no campo da filosofia. Com estas amarras, que de certa forma representam o pano de fundo que sustenta a crítica a matemática hegemônica, poderemos pensar em outras possibilidades que chamamos de intermatemáticas. Trata-se de um texto ensaístico, tendo como aporte teórico: BACHELARD (2008), BICUDO (1993), CANDAU (2002), DELEUZE (2000), DELEUZE (1996), FOUCAULT (2013), LEASK (20015), LUNA (2016), SANTOS (2002), SILVA (2010). Para atingir o objetivo geral, dividimos a análise em três partes. Primeiramente, retomamos a relação entre o processo de internacionalização do currículo (IoC) e o plano de imanência no campo da educação matemática. Em um segundo momento, discutimos a ideia de plano de imanência e a IoC. Para finalizar, articulamos aspectos metodológicos, o plano de imanência e o processo de construção conceitual na tentativa de construir possibilidade intermatemáticas. Neste movimento, destacamos não apenas a crítica a matemática hegemônica, mas, e também, indicamos os caminhos de se pensar a matemática na imanência por meio da geo-matemática, etnomatemática e a intermatemática. Palavras-chave: Plano de imanência, IoC, Educação Matemática, Intermatemática.

\section{Posibilidades Intermatemáticas: La IOC, el Plan de Imanencia y la Arquitectura de los Conceptos}

\section{Resumen:}

Cuando pensamos en las matemáticas tenemos la sensación de estar ante un tipo de conocimiento universal, que nos acerca a la verdad. La trascendencia es el espacio donde situamos este tipo de objetivación de las matemáticas. Sin embargo, la crítica a este tipo de matemáticas hegemónicas viene creciendo en el último año. Ante la hegemonía y la crítica, el objetivo de este artículo es analizar, la IoC, el plan de inmanencia, y el proceso de construcción conceptual en el campo de la filosofía. Con estas amarras, que de cierta forma representan el telón de fondo que sostiene la crítica a las matemáticas hegemónicas, podremos pensar en otras posibilidades que llamamos intermatemáticas. En el caso de que se trate de un texto ensayístico, que tenga como aporte teórico: BACHELARD (2008), BICUDO (1993), CANDAU (2002), DELEUZE (2000), DELEUZE (1996), FOUCAULT (2013), LEASK (20015), LUNA 2016), SANTOS (2002), SILVA (2010). Para alcanzar el objetivo general, dividimos el análisis en tres partes. Primero, retomamos la relación entre el proceso de internacionalización del currículo (IoC) y el plan de inmanencia en el campo de la educación matemática. En un segundo momento, discutimos la idea de plan de inmanencia y la IoC. Para finalizar, articulamos aspectos metodológicos, el plan de inmanencia y el proceso de construcción conceptual en el intento de construir posibilidad intermatemática. En este movimiento, destacamos no sólo la crítica a las matemáticas hegemónicas, sino, y también, indicamos los caminos de pensar las matemáticas en la inmanencia por medio de la geo-matemática, etnomatemática y la intermatemática.

Palabras clave: Plan de inmanencia, IoC, Educación Matemática, Intermatemática. 


\section{Introduction}

Quite often when we think of mathematics, we soon depict into our minds an image that expresses a kind of universal, immutable, trustworthy knowledge in the face of its logical and formal organization. After all, how could we question Euclidean geometry and its stylistically designed writing to represent the truth? To think of mathematics in this sense is to provide it with a status of transcendence, which, in a way, excludes the world from life and the cultures that have created it. We know that this status of transcendence has a history. As a matter of fact, it is a Eurocentric mathematics systematized in the Enlightenment period. Greek, Indian, Arabic mathematics were systematized by the Europeans who later disinherited the statute of authorship of the different mathematical cultures. Everything has become one discourse with power of universality and truth. Mathematics is forged in the expression of truth, rather superior compared to all other sciences, detached from the world contaminated by human chaos.

However, we know that the story is not a static one, interruptions do take place and the lines happen to divide. That is to say, the Eurocentric mathematics, built up by a statute of universality and transcendental organization, could see its walls collapsing, in an internal movement, as the emergence of non-Euclidean mathematics, and in an external movement, as far as the genesis of knowledge mathematician linked to intercultural relations. Given this panorama, questioning the dominant paradigms seems to be a necessity in our historical moment and it is in the field of mathematical education and intercultural studies in education that the criticisms are being here systematized.

Greatest challenges are launched in the direction of the systematization of criticism regarding the dominant, transcendental, Eurocentric mathematics. At this point, we can emphasize two aspects that are presented immediately to the questioning of Eurocentric hegemony. Firstly, in what way can we think of a methodology that allows us to discuss the critique of dominant paradigms in the field of education? Secondly, how can we organize a theoretical, epistemological and philosophical construct that allows us to make these criticisms in an oriented way?

We know that these answers could be taken as complex and the paths, rather tortuous. However, we believe that IoC, the intercultural studies in education, the concept of plane of immanence and the architecture of concepts can open up a field of intermathematical possibilities. Intermathematics, in this context, represents the questioning of the existence of a single mathematics, and that different cultures produce different mathematics. In this way, this article aims to analyze IoC, the plan of immanence, and the process of conceptual construction in the field of philosophy and mathematics education. With these moorings, which in some ways represent the background that supports the critique of hegemonic mathematics, we can think of other possibilities that we call intermathematics.

This article is divided into three parts in the form of a theoretical essay. First, we analyze the relation between the architecture of concepts and the plane of immanence in the field of mathematical education. Next, we consider IoC as a plane of immanence, a space that allows the conceptual construction articulated to a field of intermathematics possibilities. 


\section{The plane of immanence and the architecture of the concepts: considerations about the process of internationalization of the curriculum (IoC) and mathematic education.}

We are faced with two spaces that discuss different epistemological perspectives; their particularities can not be superimposed as two symmetrical figures in one scheme. On one hand, Bicudo (1993) states that Mathematics Education is characterized as an area of knowledge that is concerned with questioning mathematical comprehension, mathematical doing, social, cultural and historical meanings of mathematics. On the other hand, Leask (2015, p.9, apud LUNA, 2016, p.38) emphasizes that IoC is a process that "incorporates international, intercultural and global dimensions in curriculum content, as well as in learning objects, in activities evaluation, methodology, and all services related to a course ". Two different spaces, with their own topologies.

Highlighting the singularity of spaces, we can think of approximations. We have, in this sense, basically two paths to follow. The first is to highlight intersections objectively point to point. Silva (2010, p.2) highlights an open approach to Mathematics Education that is based on four points: "contextualization of teaching, respect for diversity, development of skills and recognition of scientific, social, political and historical-cultural purposes". However, the IoC (LUNA, 2016, p.38) "presents / displays like a process that questions the homogenization and the westernization in its consequent maintenances and reinforcements of privileges of dominant groups and languages". In this way, we can approach IoC and Mathematics Education through the questioning of cultural homogeneities. This implies a questioning of Eurocentric mathematics and the valuation of different mathematics. Ethnomathematics and intercultural education studies represent this concern objectively. The second path is that of the conceptual construction that articulates to the intelligibility and translation movements, as discussed by Santos (2002), and the Philosophy of difference, from Deleuze (2000) point of view. In this perspective, the approaches are built in the process of conceptual construction, in the relations susceptible to making the new. The two paths can be traversed constantly and it is from this perspective that we will walk

\section{The IoC as plane of immanence}

To consider IoC as a process that allows to incorporate intercultural directions in the curriculum is to consider it with a space, a space that allows to consider and to build relations between the different cultures; a space that reveals intentionally constructed absences; a space that allows translating, taking as reference system an intercultural epistemology; a space that allows to treat difference in an immanent way; a space that allows punctual translation in the epistemological fabric of the different disciplines; a space that allows us to construct other spaces of epistemological intersection. That is, we are faced with a methodology that does not simplify the real. It shows, on the other hand, its complexity and its becomings.

As we are faced with a methodology of creation, taking as substratum the result of intercultural relations, we need to delineate the spatial characteristics to consider IoC as 
space. It is, in a mathematical sense, to characterize the topology of IoC in any dimension. What we intend from that moment is to consider IoC as a plan of immanence that allows the construction of different epistemological spaces; it is a plan that, by its characteristic, allows to construct other plans.

Immanence is opposed to any external or transcendent dimension. When Deleuze (2000) formulates the ideas concerning the plane of immanence, he is not only constructing a place of circulation and conceptual circulation; there is, implicitly, a critique of the floating epistemologies that construct their systems of phenomenal explanations based on transcendental causes. This is an important aspect to consider, since IoC has as one of its pillars the criticism of homogenizing epistemologies that often use transcendental values as a shield for non-questioning. From this point of view, to consider IoC as a plane of immanence privileges the construction of an epistemological strategy that pushes IoC itself toward the plan. Strategy that avoids considering IoC as a transcendental antidote that cures all the ills of education and mathematics education. In addition to this sieve of self-evaluation, to consider IoC as a plane of immanence is to establish an epistemological place, which, through its concepts, allows us to criticize the homogenizations from a philosophical space of creation. We have the possibility to build an internal and external look.

As we shall see later, there is a relationship between concepts and the plane of immanence. Deleuze (2000, p.51) warns that the "plane of immanence is not a concept, nor the concept of all concepts". The plan of immanence is the place where concepts circulate, cross, gain speed. "It is a table, a plateau, a cup" (p.51). Further stressing the difference between concept and plane of immanence, Deleuze (2000) reinforces that concepts have different and fragmentary absolute surfaces or volumes. On the other hand, the plane of immanence is the unlimited absolute, neither surface nor volume, but always a fractal surface. Concepts are concrete assemblages while the plane is the abstract machine whose assemblages are the parts. Concepts are in the order of the event while the plane is the horizon of events. "The plane is like a desert that concepts populate without sharing. It is the concepts that are the only regions of the plane, but it is the plane that is the sole support of the concept" (DELEUZE, 2000, p.52).

In this sense, IoC is not a concept but a plane of possibilities. A plane, as Candau (2002, p.177) points out, extends his focus on "valuing cultural diversity and the need to overcome stereotypes, prejudices and cultural hierarchies." To this extent, IoC is configured as a plane of immanence that opens up a space of possibility that allows the construction of concepts based on cultural relations. And it is at this point that the studies related to intercultural education are configured. The importance of considering IoC as a plane of immanence gains a palpable scope in this moment when we think about the magnification and the infinite possibilities of interaction between the different knowledges that belong to the different cultures. We can imagine the relations, which belong to the plane of immanence of IoC, referring to the different areas of knowledge such as: intermathematics or intercultural mathematics; intercultural chemistry, intercultural physics, intercultural sociology. The possibilities are endless, and the layers are the most diverse. Layers that cross micro relations to macro relations. 
Macro relations and micro relations can be synthesized by the epistemological side that articulates with IoC. According to Luna (2016), IoC and intercultural studies are close in their principles and practice. In this way, we would face the same plane of immanence, with dimensional differences. The IoC acts in an organized way, inserting itself in the field of practices objectified in the curriculum. And intercultural studies act in the same way in micro relations, but also, it articulates more broadly in a process that goes beyond the school space. We believe it to be in this transit of varying speeds that the relations between IoC and intercultural studies weave the plane of immanence. Space without borders "the plane of immanence does not cease to weave, gigantic loom" (DELEUZE, 2000, p.54). In this sense, the plots align IoC and intercultural studies.

The relationships between IoC and intercultural studies in education at their different levels form a sort of epistemological vector that elevates absences and recognizes differences. And it is at this point that IoC, assuming its interaction with intercultural studies, overflows its limits based on the methodological images that allow its entry into the school space. IoC, in the way we are approaching, that is, as a plane of immanence, enters the school space clothed in a rationality that aligns with the homogenizing educational presuppositions. That is, IoC would function as a Trojan Horse. After crossing the walls, IoC ceases to be just a methodology to become a space of conceptual creation.

When we speak of overcoming the limits set in methodological images, we are referring to rational aspects linked to a specific epistemological picture. To overcome this epistemic barrier linked to IoC and homogeneous scientific paradigms, philosophy is called to the dance. "If philosophy begins with the creation of concepts, the plane of immanence must be considered pre-philosophical" (DELEUZE, 2000, 57). Inside the Trojan Horse, philosophy sets in with a transformation potential that grows from the inside out. To consider IoC as a plane of immanence is to give consciousness to this process that goes from methodology to philosophy.

We are not referring to all philosophies, but to those who propose to analyze, such as IoC and intercultural studies in education, the possibility of questioning the homogenisations and the resulting possibilities. That is, we are in the field of creating possibilities for the creation of concepts that take place at the cultural frontiers. In this way, if we are interested in the creation of concepts that have as substratum intercultural relations, and if we consider IoC as a plane of immanence, we can think of a prephilosophical field as Deleuze (2000) points out. If IoC overflows the limits of science and calls philosophy to go beyond its borders, to say that the plane of immanence is pre-philosophical is to install a critical becoming that expels any epistemological prescription that fixes the images that promise to excavate a liberating epistemology. The IoC in this sense is constructed looking out of the epistemic spaces already constructed. It extends its gaze to spaces that we could name in different ways: pre-mathematical, pre-scientific, pre-philosophical, sociology of absences, philosophy of thought without image. "The non-philosophical is perhaps more at the heart of philosophy than the philosopher himself" (DELEUZE, 2000, p.57). From this point of view, the non-mathematical, the unscientific, gains a voice and legitimates itself in the plane of immanence of IoC, precisely because of the attempt to broaden the plan and its space of creation. 
From this point of view, we narrow the relationship between IoC and philosophy in the attempt to construct a territory of creation in the educational field. "It is the plan of immanence that constitutes the absolute ground of philosophy, its earth or deterritorialization, its function on which it creates its concepts" (DELEUZE, 2000, p.58). It is like a land of creation, in the expedition of new lands - deterritorialization - that the IoC considered as plane of immanence is legitimized in the field of philosophy. Not as a definite plan in a certain area of knowledge, but rather in the escape movement of territories that can become homogenizing machines. The speed of creation and expansion of the plane of immanence in this way needs to be greater than the rate of aging of the epistemological slopes that gratify the real and shrink the complexity of the world.

We are faced with an alternative: the non-legitimacy of transcendent epistemological trends and the absolute chaos that governs the real. "The plane of immanence is like a cut in chaos and acts as a sieve" (DELEUZE, 2000, p.59). Sieve in the fractal geometric sense where one looks for a system that governs the chaos without diminishing its intensity and complexity. If the plane of immanence is a cut in chaos, it is only fair to conclude that there is "a multiplicity of plans, since no one would embrace all chaos without falling into it" (DELEUZE, 2000, p.68).

In the movement to consider IoC as a plane of immanence, we overfly the features of the plan and the possibility of constructing a space of conceptual creation. The approximation between IoC and the Deleuzian plane of immanence is not restricted to aspects of delimitation and theoretical foundation. Nor does it mean to legitimize the already established through more sophisticated tools. We believe that this approach increases the base power of establishing movements of creation and questioning of the hegemonic cultures present in the space of education. To consider IoC as a plane of immanence is to create a space of argumentation that is released from a process, as we will see later, that penetrates the curriculum and the most different educational practices. In this sense, IoC goes beyond its method and gains aspects of actuality and virtuality in the plane of immanence.

In this sense, IoC can be considered as a theory that defends cultural multiplicities. It questions the monocultural and ethnocentric character; theory that articulates with methodological aspects with reference in the intercultural studies in education. However, all cultural or immanent multiplicity implies current and virtual elements. According to Deleuze (1996, p. 49), "There is no purely current object. Every current is surrounded by a fog of virtual images". In this perspective, every current is surrounded by virtual circles that have other higher order virtues in the center. It is called virtual in that its brevity and speed keep them under the principle of unconsciousness. (DELEUZE, 1996).

Speed that transforms the prevailing into virtual and the virtual into the prevailing. "Object and image are both virtual here, and constitute the plane of immanence where the present object dissolves" (DELEUZE, 1996, p.50). In this way, IoC presents current and virtualities that make up its plane of immanence. Virtual aspects that make up the plane of immanence open the possibility of constructing concepts, precisely in the passage that occurs between the virtual and the current. Affirming the existence of virtual aspects that make up the plane of immanence is due to the importance of the construction of the different. Otherwise, we would be throwing data on a table expecting 
the random results to update in the form of numbers. The plane of immanence is not limited to objective current aspects, it expands into a field of virtual possibilities that in the movement can become current. That with the infinite planes of immanence. With IoC's immanence plane, virtual factors gain peculiar importance. For when we question the monoculture of knowledge, or Eurocentric culture, we are not only concerned with the artifacts or knowledge produced by a set of peripheral cultures. Our gaze extends to the virtuality produced in intercultural relations. To consider IoC as a plane of immanence is to add to the intercultural relations virtual aspects that can be released by the constructing interpreter. It is in intercultural relationships that cultural virtualities can become current.

On the same scheme we have the prevailing and the virtual in a single time. Perhaps this text is the liberation of the virtual, as far as IoC is concerned; it is the virtuality of IoC weaving its articulations with philosophy and science. And it is in this exchange between the current and the virtual that the crystals are constructed. "It is on the plane of immanence that crystals appear. The present and the virtual coexist, and they enter a narrow circuit that brings us constantly from one to the other "(DELEUZE, 1996, 54). This narrowing in the form of a circuit, in which the current and the virtual coincide, is what IoC allows to unleash in the field of education. And also, looking briefly, to consider IoC as a plan of immanence is to reduce the distances between the prevailing and the virtual. Virtual, plan of immanence, the prevailing, methodologies already built by IoC. What we have done so far has been to give consciousness to this narrow circuit.

Map 1: Plane of immanence

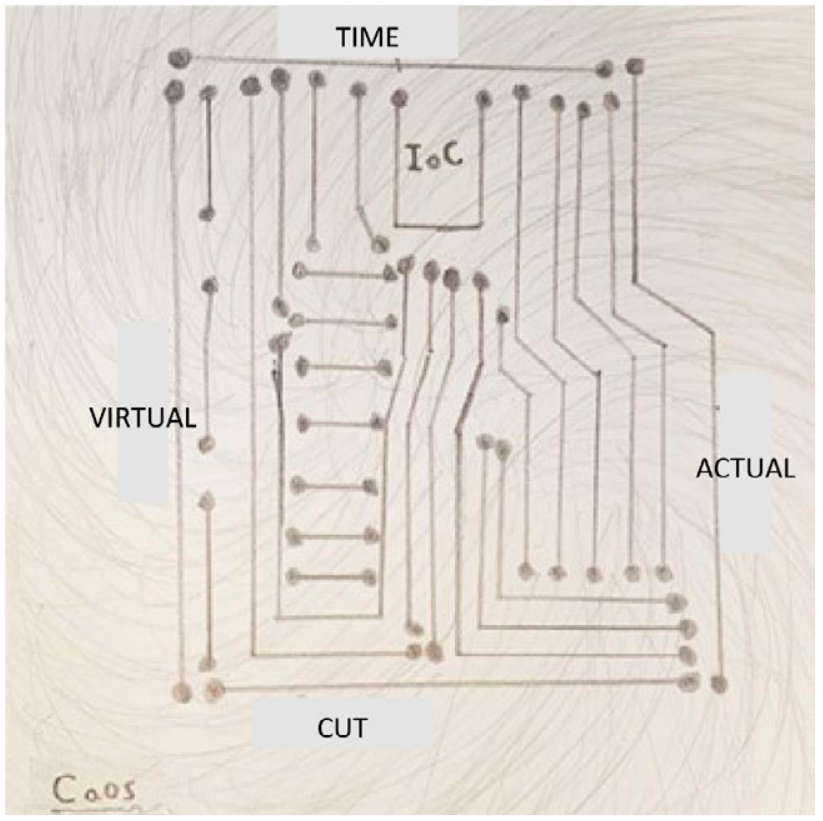

Source: the researchers.

One more aspect needs to be considered, so that we can firm the ties and consider IoC as a plane of immanence. If the transition from the actual to the virtual and from the virtual to the actual is the movement that is contained in the plane of immanence, 
as Deleuze (1996) asserts, we need to consider the temporal implications. To consider the actual and the virtual is to consider two temporal dimensions. The first one of the present that passes continuously through a supposed movement in a single direction. The actual, in this sense, is projected into the present and passes as this time runs out. The virtual, in turn, is also present in a smaller scale. And it is in the past that the virtual is conserved, that is, the present passes in its scale and the past conserves and conserves in its scale. (DELEUZE, 1996).

The relationship between the actual and the virtual is established in circuits that go from the actual to the virtual and the virtual to the actual in a physical temporality (map 1). The plane of immanence contains at one and the same time the updating of this movement (DELEUZE, 1996). In this way, we place on the IoC's plane of immanence historical virtual temporal aspects and the actuality that presents itself with each new pop of the present. Thus, the IoC plane of immanence contains aspects that involve the past and the present in a movement that weaves not only the epistemic space of IoC's performance, but also, and in a specific way, establish relations that establish a geography of thought. In this way, translation and intercultural relations are updated in a construct that is organized in spaces in which the present and past temporalities are virtualized and updated at each moment. In the final analysis, to consider IoC as a plane of immanence is to retake the possibilities of construction that permeate the present and the past in a translation movement that creates concepts with a directed look at intercultural relations. Process that is established on the plane of immanence, and that sustains the conceptual construct that we will analyze in the next section.

\section{The IoC and the concepts architecture: articulations and intermathematical possibilities}

The Trojan Horse, by its repeated appearance in the field of the language, became a recurring history in the popular sayings in the most different variations. In this way, as we know, it is a wooden horse built by the Greeks as a strategy to take the city of Troy. Simple strategy, that hid inside, of a trophy that seemed resplendent, the enemy that later would take the city.

We believe that IoC in its procedural character resembles the popular story told in Homer's Iliad. From the point of view of the entry of intercultural movements into education, IoC as a process, as we will see later, allows us to transform the relations established in the school space from the inside out, similar to the Greek strategy of the Trojan Horse. From the point of view of the plane of immanence, that is, space that allows the construction of concepts, IoC implies a methodology that does not simplify the real. Simplification in a Cartesian sense as Bachelard (2008) states. In this way, IoC, as Trojan Horse, allows the insertion of intercultural movements in education, and as a plane of immanence, it extends the analyze at different levels: epistemological, philosophical, scientific, social and cultural.

Let us return, at this moment, to the Trojan horse and IoC. IoC resembles the Trojan Horse not because of the character of warfare through the enemy, but because of its potential for transformation. As we will see later, the IoC as a specific process, through 
five stages proposed by Leask (2015), a methodology that allows the internationalization of the curriculum through international studies, in a systematic and organized way. We can say that this is a methodology aesthetically organized in tables, because it has stages that separate the process into small pieces that work in cycles. In this way, its aesthetics is designed in a quadruplex and procedural format. Considering the entry of this methodology, constructed in this way by Leask (2015), it is possible to observe that its aesthetics resemble the school space. According to Foucault (2013, p.143), since the XVIII century schools, hospitals, and asylums have become disciplinary mechanisms that have been constituted as "living pictures" that transform the confused crowds into organized multiplicities. States before a series of display and check devices. Foucault (2015) still mentions that this organization does not only happen on an objective level, such as the organization of portfolios, or the division and organization of time. It happens through the techniques of power and the processes of knowing. In this way, there is a process of organization and domination of the multiple. It is possible to observe, from this point on, that the educational space and its mechanisms are projected at the epistemological level in the curricular organization through a grid system in the row column format. In this sense, we have Leask (2015), which systematizes IoC as a process that allows the systematic linking of intercultural studies in education; in another sense, Foucault (2015) analyzes the systematization of disciplinary mechanisms and the construction of organizational frameworks. And it is at this point that we can consider the IoC and the stages pointed out by Leask (2015) as a Trojan Horse. At the bottom it is a problem of anchorage made by the aesthetic way, in the quadruple sense. To consider IoC as a plane of immanence requires a strategy of entry into school space, our Trojan Horse, which, after passing through school walls, may reveal its potential for transformation into a movement that aesthetically aligns with the mechanisms revealed by Foucault (2015) because it is a method also organized in a quadric way. But otherwise, and within, it hides a machine that expands intercultural relations immanently. It is this aspect that explains the geometric parallelism between the Trojan Horse and the lines that belong to the educational space.

Map 2: The IoC and the Trojan horse

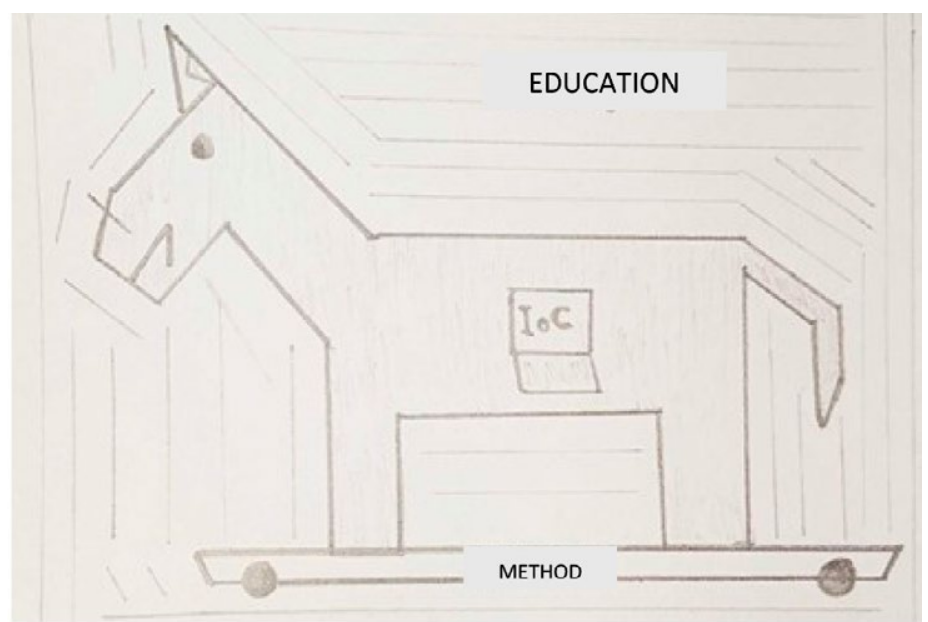

Source: the researchers. 
Having analyzed the process of IoC's entry into education, which, in principle, resembles aesthetic mechanisms that work in cadres, we would like to take a step towards the relationship between methodology and epistemological development. Bachelard (2008) mentions that the new scientific spirit, referring to the new non-Cartesian scientific, non-Euclidean, microphysical geometries, and the atomic perception of the real, has installed a critical movement in the scientific environment internally. Space supposedly protected by rationality but in its development starts to create fissures. This is the case of non-Euclidean geometry, which develops from the inability to prove that on any surface we can always construct parallel lines. What we know is not possible about a sphere. In this way, the epistemological development movement, as in the case of non-Euclidean geometry happens in the sense axiom, method and epistemology. It is by method and its contradiction in the verification in space that other reflections are generated. Critical of the Cartesian method, Bachelard (2008) indicates that the Cartesian method simplifies the real and homogenizes the relations. The same author points out that modern scientific movements have resumed the possibility of thinking about methodologies that do not simplify the real, as did Cartesianism. The influence of these new scientific aspects led to the emergence of reflections ranging from method to epistemology, from method to philosophy, and from method to science itself (BACHELARD, 2008). The IoC in this sense, besides working as Trojan Horse, as we saw above, is shown as a methodology that does not simplify the real, which considers the different intercultural relations and their complexity. If, as Bachelard (2008) affirms, modern science and its methodologies have raised the possibility of reflecting on new possibilities of construction that propagate in the direction of epistemological fields well defined for its exterior, reaching other fields of knowledge, IoC is characterized as a methodology that in its interior development allows to create fissures that go from the method to other fields of knowledge.

Having defined the aesthetics of IoC's entry into education as a Trojan Horse, its potential for creation in the plane of immanence, and the sense of transformation that propagates from the method to other areas of knowledge, we can more closely analyze the construction process conception that happens on the plane of immanence and the stages of IoC. The stages, in turn, are suggested by Leask (2015), as synthesized in the following map:

Map 3: The process of internationalization of the curriculum

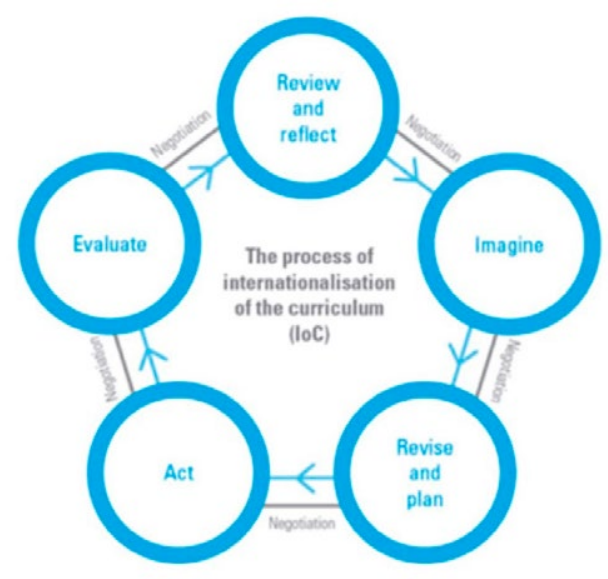

Source: Leask (2015, p.42) 
As we can see in Map 3, the process of internationalization is divided into five stages. Leask (2015) uses the concept of curriculum in its formal, informal and hidden dimensions to signal the relationship between the curriculum and the teaching and learning practices that circulate in the school space. In this way, internationalizing the curriculum means building contact zones between the intercultural studies in education and the curriculum, so that there is a transposition in the practices carried out in the school space. Contact zones constructed through a process divided into stages: review and reflect; to imagine; review and plan; Act; to evaluate. The first stage - review and reflection - is aimed at analyzing the degree of openness to the different and the place of interculturality in the curricular components (LEASK, 2015). It is at this stage that we have the accommodation of the Trojan Horse, the contour lines are observed and the anchorage established. From this point of view, we return to this stage, which is presented in our eyes, according to the systems of reference that guide our perception of what is objectified in the curriculum. Thus, one does not only observe what is contained in the curricula, or what is current in Deleuze's (1996) terms. Our gaze also turns to the system of reference that guides the analytical gaze. In this sense, there is a double diagnosis: the first with respect to the degree of internationalization of the curriculum, with regard to the homogenizations and the place that the intercultural reflexes occupy in the base of the curricular components; the second, which is indivisible in relation to the first, twists the gaze itself, as an observer that filters and classifies the homogeneities according to the reference system connected to the observer.

After the curricular revision and reflection of the gaze, we pass to the second stage - that of the imagination. We believe that this stage is the point where IoC shows its differential of transformation and conceptual construction after the esthetic adjustment promoted by Trojan Horse. As we are already inserted in the educational environment, close to the demands of teachers and managers, the plane of immanence as a possibility of conceptual construction is not in the academy or in a research group, which is often far from practices carried out in the educational space. The opening of a creative space takes place locally in the same space where education takes place. In this way, for Leask (2015), the stage of the imagination is characterized by questioning the cultural foundations of our disciplines, and thinking about possibilities of insertion of international and intercultural dimensions into the formal, informal and hidden curriculum.

The stage of the imagination, in this wake, can be constituted as a moment in which, when questioning the cultural pillars that sustain our disciplines, the virtualities contained in the plane of imannence of the IoC detach in the form of a current that is objectified in the curriculum. From this point of view, we can imagine that the internal consequences of the curricular organization form a narrower movement in the stage of the imagination, as a lever that allows the construction of practical possibilities with regard to the insertion of different intercultural practices in the school environment. However, to consider IoC as a plane of immanence is to awaken a movement, which can begin at the stage of the imagination, changes of direction and direction of the place where the dominant cultures are questioned; we are no longer in the sense of transcendence to immanence. In this way, IoC acts as a trigger that awakens a movement that not only allows the insertion of other cultural knowledge in the curriculum, but also excites the 
possibility of constructing concepts ranging from immanence to immanence or from land to other lands, process of deterritorialization according to Deleuze (1996).

After the imagination, we enter the stage of revision and planning. In this, as Leask (2015) states, we question the changes that can be made in a certain course or educational space. This stage is characterized by the architecture of practices that can be taken in the time and space available. It is ideally to transpose the possibilities analyzed in the imagination into the field of possible practices. They are the currents resumed by the intercultural studies that leave the Trojan Horse and settle in the channels that form the structure of the school space. The rationalities, the dominant cultures, the centralities, are questioned, as we have seen in the stage of the imagination. These, in turn, transform and are transformed into a game of continuous exchanges that make up a geography of knowledge. Even directing the practices, the plane of immanence is objectified, as a space of possibilities. Possibilities that are objectified in the form of a conceptual character (DELEUZE, 2000), who carries the opening prerogatives brought about by the stage of the imagination. To create a conceptual character that is linked to IoC's plane of immanence, a challenge that brings us back to the relation between imagination in the field of possibilities and its presentation in the field of practices.

After the previous three stages, we come to the following two: action and evaluation. According to Leask (2015), these last two stages are characterized in answering: what were the goals of internationalization achieved? And what can be taken as a reference for a new methodological cycle that repeats itself continuously? Luna (2016) reinforces the need, in this methodological moment, to analyze the whole process in order to generate feedback. It is about observing the openings that the plane of immanence causes in the chaos and the possibility of constructing circuits of actuality and virtuality. However, action and evaluation are made in motion, where the cycle repeats itself and the field of possibility is broadened in the methodological sense, with regard to the school practices of intercultural analysis, and in the epistemological sense in the possibility of conceptual creation and intelligibility.

So far, we have moved towards building a double movement. We think of IoC as a methodology that questions the monocultural dogmas and establishes a process capable of adapting to school aesthetics, and that open the possibility of expanding intercultural discussions to each new cycle divided into five stages, as suggested by Leask (2015). With Bachelard (2008), we observe that theoretical-methodological spaces can unleash in their internal construct movements that influence the creation of new spaces of analysis such as non-Euclidean geometry and micro epistemologies that mix the perception of the world that we have in our historic moment. Inheritance of a recent time, but that is already lodged in our look. Approaching Leask (2015) and Bachelard (2008) is to think of a method that allows creation. That brings possibilities of creation in the adaptation of its architecture to the educational environment. However, this is the first path, that is, to construct a method that allows the creation of intercultural relations in the educational space, in the methodological movement itself. The second path seems to be more winding. To consider IoC as a plane of immanence, as Deleuze (2000) analyzes, is to move IoC into a philosophical space. Space of the philosophy of difference and its infinite implications. If the first path highlights the creative power of IoC, with regard to inter- 
cultural relations in educational space, the second path is established in the becoming that these analyzes can provoke in other areas of knowledge.

We need, in this sense, to bring IoC closer to the field of philosophy, to highlight the points that allow us to make this approximation. As we pointed out previously, we could think objectively in an analytical selection process that takes as a reference criteria selected a priori. This, in turn, would lead us to observe two spaces that, approximate, generate an intersection in the molds of a Venn diagram. Since we are considering IoC as a plane of immanence, that is, as a space of creation that allows the construction of intercultural relations, what brings IoC closer to the field of philosophy is its creative character, or, as Deleuze mentions (2010, p.10), "Philosophy is the art of forming, of inventing, of fabricating concepts". We believe in this art that the approach of IoC and philosophy is effective.

The immediate question we can ask at this moment is: what is a concept? According to Deleuze (2010, p.27), "There is no simple concept. Every concept has components and is defined by them. It has a figure. It is a multiplicity, though not all multiplicity is a concept - in addition, every concept refers to a problem, to problems without which they would not make sense without remitting to their solutions (DELEUZE, 2010). We are faced here with a problem or set of problems identified by $\mathrm{IoC}$ in regard to the questioning of the dogmas that support the practices of homogenization in the educational space. In this sense, we can think of the construction of concepts related to different areas that invert the relationship between problem and solution. From this point of view, to consider IoC as a plane of immanence and conceptual construction space is to highlight the relation of dependence that exists between solution and problem. It is in the solutions, updated by the concepts, that the problems are evident and not the inverse.

Concepts are not built in emptiness. Every concept has a history, which often relates to other concepts belonging to other plans. On the other hand, every concept has a becoming that reaffirms its relation with concepts situated in the same plane of immanence. It is on the plane of immanence that relationships are constructed and concepts are created (DELEUZE, 2010). Creation that happens in the relationship between different areas of knowledge located culturally. In this way, the components of a concept become effective in an " $\mathrm{a}, \mathrm{b}$ domain belonging to both $\mathrm{a}$ and $\mathrm{b}$, where $\mathrm{a}$ and $\mathrm{b}$ become indivisible. (...) Each concept will therefore be considered as the point of coincidence, of condensation or accumulation of the components themselves "(DELEUZE, 2010 p.32).

We can observe at that moment that if philosophy is the art of constructing concepts; the IoC and intercultural studies in education constitute the art of building intercultural relations, build intelligibility between different cultures. If Deleuze (2010) constructs in his argument that, as we go through different areas of knowledge, art, science and philosophy, we have the possibility in the relations to construct new concepts, the IoC plane uses this perspective to include a new component in conceptual construction process. That is, in addition to the conceptual components, outlined by the philosophy of difference, we place this approach in the field of cultures. Intercultural relations, in this sense, add to this process cultural aspects.

Situating the process of conceptual construction as a barrier that allows the construction of intercultural relations allows us to situate more precisely the knowledge that belongs to different cultures. The conceptual components of indigenous geometry articulate 
with Euclidean geometry in a movement of incompleteness that fills itself in the act of approximation. To bring the philosophy of Deleuze (2010), with intercultural studies in education and $\mathrm{IoC}$, closer to our capacity to observe intercultural relations in their micro relations. We do not consider intercultural relations in a macro form, in molar relations, as Deleuze (2012) indicates. We are faced with the molecular, conceptual relations belonging to the micro relations that take place between the different cultures in a relation that can be characterized as follows: indigenous - mathematics - Eurocentric; indian - science - brazilian; African - art - Mexican; mathematics - sociology - philosophy; and so on.

After narrowing down the process of constructing intercultural relations at the conceptual level, situated on the IoC's plane of immanence, we are ready to analyze mathematical education in this perspective. Perspective that articulates with the plan of immanence of IoC, methodological and procedural aspects, conceptual construction, and, consequently, epistemological and historical discussions related to cultural mathematical becoming, which also articulates with other cultures and areas of knowledge such as sociology, philosophy, art and science. If, to do research in education or more specifically in mathematics education, we need, as Bicudo (1993) indicates, to have a certain mastery of a vast horizon of knowledge, such as history, philosophy and mathematics itself, to situate mathematics on the IoC's plane of immanence is to potentiate these relations in a movement that ultimately seeks to build a world of intermathematical possibilities.

\section{Final Considerations}

The purpose of this article was to analyze the relationship between IoC, the plane of immanence and the conceptual construction process, so that we can think of the background that criticizes hegemonic mathematics. This approach allows us to think of the already established as well as in a world of possibilities. What is visible to us is what we could name as a kind of transcendent, hegemonic mathematics that has its origin in Eurocentric cultural immanence. We are facing a project of domination, in which rationality represents a code that has become ontological. Otherwise, we can reflect upon the consequences of this criticism at an epistemological level a posteriori.

After the construction of methodological, epistemological and philosophical aspects, we can trace the path of intermathmatic possibilities. This path of non-transcendence can be systematized in three layers: geo-mathematics, ethnomathematics and intermathmatics. The combination of these three points allows us to think of mathematics in immanence. Geo-mathematics argues that mathematics depends on the geography, space-time, daily practices of a particular people. Ethnomathematics, on the other hand, asserts that different cultures produce different mathematics and that there are relations of power that are based on the discursive threads that cross them. And finally, the intermathematics, that is in the immanence of the relations signed by the different cultures.

These three points form a chain of relationships that are based on IoC, on the plane of immanence, on the process of conceptual construction and on intercultural studies in education, form a fabric of possibilities that widens its space in the direction of an intercultural thought. Thoughts require an interpreter, a subject, an epistemological reference; translation carries within itself the horizon of intercultural events. 


\section{References}

BACHELARD, G. O novo espírito científico. Rio de Janeiro. Tempo Brasileiro, 2008.

BICUDO, M. A. V. Pesquisa em educação matemática. São Paulo. Pro - posições, 1993.

CANDAU, V. M. Sociedade, Educação e Culturas(s). Rio de Janeiro: Vozes, 2002.

DELEUZE, G. Diferença e repetição. Lisboa: Relógio d Água, 2000. 493 p.

DELEUZE, G. O atual e o virtual. Paris: Diálogos, 1996.

FOUCAULT, M. Vigiar e Punir. Editora Vozes, 2013.

LEASK, B. Internationalizing the curriculum. Abingdon: Routledge, 2015.

LUNA, J. M. F. (org.) Internacionalização do currículo: Educação, interculturalidade, cidadania global. Pontes: 2016.

SANTOS, B. S. Para uma sociedade da ausência e uma sociedade das emergências. Revista crítica das ciências sociais. 2002. p. 237-280.

SILVA, N. M. A. Educação matemática e totalidade: um estudo crítico epistemológico. Unesp de Rio Claro - SC, 2010.

\section{Juliano Bona}

Has a degree in Mathematics from Universidade Regional de Blumenau - FURB (2005). Has experience in teaching Mathematics at elementary education at public education system in Timbó, Santa Catarina, Brazil. Has a Master's degree in Education from Universidade Regional de Blumenau - FURB (2010). Has experience in Higher Education in the following areas: Mathematics Education, Differential and Integral Calculus, Geometry and Linear Algebra. He is currently a doctorate student in Education - UNIVALI - Universidade do Vale do Itajaí.

\section{Camila Thaisa Alves Bona}

Has a degree in Languages (2008) and a Master's in Education (2010) from Universidade Regional de Blumenau (FURB). Works as Portuguese and English teacher at elementary education and early childhood education at public and private education systems. Doctorate student in the Postgraduate Program in Education - UNIVALI - Universidade do Vale do Itajaí.

\section{José Marcelo Freitas de Luna}

Has a degree in Languages from Universidade Federal da Paraíba (1985); Master's degree in Languages (English and Correspondent Literature) from Universidade Federal de Santa Catarina (1990), with interuniversity exchange at the University of Birmingham (England); specialization in University Administration by the Interamerican University Organization and Universidade Católica de Goiás, with an internship at the University of Ottawa (Canada); Specialization in Management of International Technical Cooperation, by FEA / USP; Doctorate in Linguistics from Universidade de São Paulo (1999), with interuniversity exchange doctorate at Cambridge University (England); and postdoctoral fellowship, between 2010 and 2011, at the University of Texas at Austin (United States). 